\title{
Cost-effectiveness of personalized supplementation with vitamin D-rich dairy products in the prevention of osteoporotic fractures
}

\author{
O. Ethgen $^{1}$ • M. Hiligsmann ${ }^{2} \cdot$ N. Burlet ${ }^{1} \cdot$ J.-Y. Reginster ${ }^{1}$
}

Received: 27 July 2015 / Accepted: 7 September 2015 / Published online: 22 September 2015

(C) The Author(s) 2015. This article is published with open access at Springerlink.com

\begin{abstract}
Summary Titrated supplementations with vitamin D-fortified yogurt, based on spontaneous calcium and vitamin D intakes, can be cost-effective in postmenopausal women with or without increased risk of osteoporotic fractures.

Introduction The objective of this study is to assess the costeffectiveness of the vitamin D-fortified yogurt given to women with and without an increased risk of osteoporotic fracture. Methods A validated cost-effectiveness microsimulation Markov model of osteoporosis management was used. Three personalized supplementation scenarios to reflect the $\mathrm{Ca} / \mathrm{Vit} \mathrm{D}$ needs taking into account the well-known variations in dietary habits and a possible pharmacological supplementation in $\mathrm{Ca} /$ Vit $\mathrm{D}$, given above or in combination with anti-osteoporosis medications: one yogurt per day, i.e., $400 \mathrm{mg}$ of $\mathrm{Ca}+200 \mathrm{IU}$ of Vit D (scenario $1 \mathrm{U}$ ), two yogurts per day, i.e., $800 \mathrm{mg}$ of Ca+ $400 \mathrm{IU}$ of Vit D (scenario $2 \mathrm{U}$ ), or three yogurts per day, i.e., 1, $200 \mathrm{mg}$ of $\mathrm{Ca}+600 \mathrm{IU}$ of Vit D (scenario $3 \mathrm{U}$ ).

Results One yogurt is cost-effective in the general population above the age of 70 years and in all age groups in women with low bone mineral density (BMD) or prevalent vertebral fracture (PVF). The daily intake of two yogurts is cost-effective above 80 years in the general population and above 70 years in the two groups of women at increased risk of fractures. However, an intake of three yogurts per day is only cost-effective
\end{abstract}

J.-Y. Reginster

jyreginster@ulg.ac.be

1 Department of Public Health, Epidemiology and Health Economics, University of Liège, CHU Sart Tilman B23, 4000 Liège, Belgium

2 Department of Health Services Research, Maastricht University, Maastricht, The Netherlands above 80 years old in the general population, as well as in women with low BMD or PVF.

Conclusions Our study is the first economic analysis supporting the cost-effectiveness of dairy products, fortified with vitamin $\mathrm{D}$, in the armamentarium against osteoporotic fractures.

Keywords Cost-effectiveness $\cdot$ Dairy products $\cdot$ Fracture . Osteoporosis $\cdot$ Yogurt

\section{Introduction}

Osteoporosis is defined as a systemic skeletal disease characterized by low bone mass and microarchitectural deterioration of bone tissue, with a consequent increase in bone fragility and susceptibility to fractures [1]. The high societal and personal costs of osteoporosis pose challenges to public health and physicians [2]. Adequate dietary intakes of key bone nutrients such as calcium, vitamin $\mathrm{D}$, and proteins contribute to bone health and reduce the risk of fracture later in life [2-4]. A recent European consensus recommends adequate vitamin D intake of $800 \mathrm{IU} /$ day to maintain serum $25-\mathrm{OH}$ hydroxyvitamin D levels $>50 \mathrm{nmol} / \mathrm{L}$ as well as calcium intake of $1000 \mathrm{mg} /$ day $[3,5]$. There is a high prevalence of vitamin $\mathrm{D}$ insufficiencies in the elderly and dietary calcium is low in many postmenopausal osteoporotic women [2, 5-8]. Dietary sources of nutrients are the preferred option and pharmacological supplementation should only be targeted to those individuals who do not get sufficient calcium from their diet and who are at increased risk for osteoporosis [2]. As calcium is mainly provided in dairies, calcium and vitamin D-fortified dairy products (e.g., yogurt, milk,...) providing at least $40 \%$ of the recommended nutrient intake (RNI) of calcium $(400 \mathrm{mg}$ ) and $200 \mathrm{IU}$ of vitamin D per portion are considered 
valuable options that are likely to improve long-term adherence [2]. Indeed, dairy food has been shown to provide calcium with good compliance compared to pharmacological supplements [9]. This phenomenon might be emphasized by recent publications suggesting that pharmacological calcium supplements might be associated with adverse health events of which dairy products intake appears to be deprived [10]. Amazingly, though this recommendation is claimed to be justified both in terms in efficacy and cost-effectiveness, few studies targeted the cost-effectiveness of calcium and vitamin $\mathrm{D}$, and none, so far, assessed the economic value of fortified dairy products given to women at increased risk of fractures $[11,12]$. Whereas low intake in calcium and vitamin D seems ubiquitous in most European countries [2, 6-8], there are significant variations in the amount of these nutrients that postmenopausal women receive, hence making the case for a personalized supplementation, tailored on their real needs rather than systematically offering to all subjects the "standard" dose of $1 \mathrm{~g}$ of calcium and $800 \mathrm{IU}$ of vitamin D per day. Therefore, the objectives of this study was therefore to assess the costeffectiveness of the administration of one to three portions per day of a vitamin D-fortified yogurt given to elderly women with and without an increased risk of osteoporotic fracture.

\section{Material and methods}

Due to the previously described wide variation in calcium and vitamin D intake in women with and without an increased risk of osteoporosis $[2,6,8]$, we considered three scenarios, i.e., daily administration of one, two, or three portions of a yogurt fortified with vitamin $\mathrm{D}$ (each portion providing $400 \mathrm{mg}$ of calcium and $200 \mathrm{IU}$ of vitamin D) to reach the recommended daily intake of $1000 \mathrm{mg}$ of calcium and $800 \mathrm{IU}$ of vitamin D. The target population focused on women aged 65,70 , or 80 years, without increased risk of osteoporosis, or with low bone mineral density (BMD), defined as a T-score $<-2.5$ at the spine and/or at the femoral neck or with a prevalent vertebral fracture (PVF).

We adapted an extensively published and validated costeffectiveness model of osteoporosis management [11, 13]. The model is a microsimulation Markov model designed with TreeAge pro (TreeAge Pro Inc, Williamston, USA). The occurrence of fractures at individual ages is modeled through a health-state transition process (Markov model). Individuals begin one at a time in the non-fracture state and progress every 6 months (cycle length) according to age-specific fracture risk through the non-fracture state, hip fracture state, vertebral fracture state, wrist fracture state, or other fracture state. Similarly, individuals with a PVF begin one at a time in this state and progress also every 6 months to other fracture states according to age-specific fracture risk adjusted by the presence of this prior vertebral fracture. Microsimulation modeling is a way to integrate memory by taking into account the full history of the patient. For instance, the occurrence of fractures as time goes by is taken into account by tracker variables to adjust the future risks of fractures [13]. The model has a lifetime horizon for each simulated patient. All patients can die from background mortality from any health state (Fig. 1).

The risk of hip fracture was derived from the Belgian national database of hospital bills [14]. Since the incidence of non-hip fracture was not known, we applied the age-specific ratio of index fracture to hip fracture in Belgium as found in Sweden [15]. These risks of fractures in the general Belgian population were further adjusted for women with BMD Tscore $<-2.5$ and women with a PVF using a method described elsewhere [16].

We assumed that individuals who had a previous fracture were at increased risk of a subsequent fracture at the same location. These increased relative risks of fracture were 2.3, 4.4, 3.3, and 1.9 for hip, vertebral, wrist, and others fractures, respectively $[13,17,18]$. An increased risk of subsequent fractures at different sites from that of prior fractures was not modeled in the absence of supporting data except for a subsequent hip fracture following a vertebral fracture with an increased risk of 2.3 [13].

The age-specific mortality rates were taken from official Belgian demographic statistics for the year 2012 (Pubic Federal Department of Economics, Brussels, 2015). We assumed that hip fracture increased death probabilities by 1.53 in the first 6 months following the fracture, by 1.75 in the $6-$ 12 months following the fracture, and by 1.78 in subsequent year, as evidenced in a meta-analysis [19]. The same excess mortality was assumed for vertebral fracture but not for wrist and others fractures.

Utility data of the general population and relative fracture disutility were taken from a published systematic review [20]. When a second fracture occurred at the same site, the disutility applied to the first fracture was reduced by $50 \%[13,21]$.

$\mathrm{Cat} / \mathrm{Vit} \mathrm{D}$ supplementation effectiveness in the reduction of fracture incidence was taken from a recent study [11] that reviewed and synthesized meta-analyses previously published on the subject. $\mathrm{Ca} / \mathrm{Vit} \mathrm{D}$ supplementation has been shown to reduce the risk of hip fracture by $18 \%(\mathrm{RR}=0.82,95 \% \mathrm{CI}$ 7.1-0.94; meta-analysis of 6 trials including 45,509 patients) [22]. The risk of vertebral fracture by $13 \%(\mathrm{RR}=0.87,95 \%$ Cl 0.75-1.01; meta-analysis including 45,164 patients) [23] and the risk of non-hip non-vertebral fracture by $20 \%$ (RR $=$ $0.80,95 \% \mathrm{Cl} 0.72-0.89$; meta-analysis of 9 trials including 32,285 patients) [24].

Patients were assumed to follow $\mathrm{Ca} / \mathrm{Vit} \mathrm{D}$ supplementation for 3 years. The protective effect of $\mathrm{Ca} / \mathrm{Vit} \mathrm{D}$ supplementation on fracture risk was then assumed to decline linearly for a period equal to the supplementation duration (i.e., 3 years). This assumption is aligned with previous cost-effectiveness analyses of osteoporosis treatment $[1,11,25]$. 


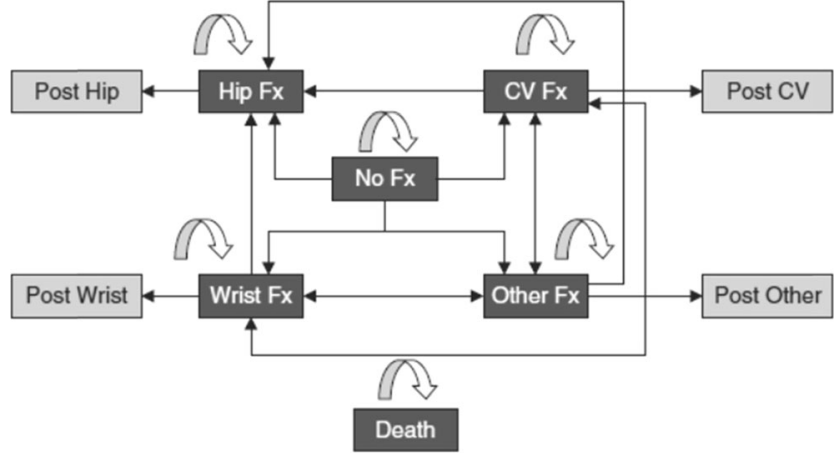

Fig. 1 Model structure. Transition to death and from post-fracture (Fx) states to any fracture states. Death and no-fracture states were excluded from the diagram for simplicity. $C V$ clinical vertebral fractures (from 9)

The perspective for the cost calculation was that of the Belgian Health care payers (government and patients) as recommended in the Belgian pharmacoeconomics guideline [26]. Only direct medical costs were taken into account. The hospitalization cost of hip fracture was retrieved from the Belgian national database of hospital bills for the year 2007. Extra costs in the year following a hip fracture were derived from a prospective study of 159 women [27]. The costs of non-hip fractures were estimated relative to hip fracture [28]. We assumed that non-hip fractures were not associated with longterm costs.

In the absence of official pricing data, as opposed to pharmaceuticals for instance, the price of dietary $\mathrm{Ca} / \mathrm{Vit} \mathrm{D}$ supplementation products was derived from the observed market prices of a yogurt containing $400 \mathrm{mg}$ of $\mathrm{Ca}$ and $200 \mathrm{IU}$ of Vit $\mathrm{D}$ per unit. The average price per pack of $4 \mathrm{U}$ was $1.37 €$, i.e., $0.34 €$ per unit.

We included the cost of one general practitioner visit $(23 €)$ per year of supplementation and the cost of one bone densitometry at years 1 and 3 ( $59 €=36 €$ the cost of bone densitometry $+23 €$ the cost of one additional general practitioner visit).

All costs were expressed in 2014 euros using the official Belgian health price index (Public Federal Department of Economics, Brussels, 2015).

Three supplementation scenarios were considered to reflect the $\mathrm{Ca} / \mathrm{Vit} \mathrm{D}$ needs of the female population with osteoporosis or with PVF, taking into account the well-known variations in dietary habits and a possible pharmacological supplementation in $\mathrm{Ca} / \mathrm{Vit} \mathrm{D}$, given above or in combination with antiosteoporosis medications: one enriched yogurt per day, i.e., $400 \mathrm{mg}$ of $\mathrm{Ca}+200 \mathrm{IU}$ of Vit D (scenario $1 \mathrm{U}$ ), two enriched yogurt units per day, i.e., $800 \mathrm{mg}$ of $\mathrm{Ca}+400 \mathrm{IU}$ of Vit D (scenario $2 \mathrm{U}$ ), or three enriched yogurt units per day, i.e., 1, $200 \mathrm{mg}$ of ca $+600 \mathrm{IU}$ of Vit D (scenario $3 \mathrm{U}$ ). With a unit price of $0.34 €$ per yogurt, the annual costs were 125,250 , and $375 €$ for the $1 \mathrm{U}, 2 \mathrm{U}$, and $3 \mathrm{U}$ dietary $\mathrm{Ca} / \mathrm{Vit} \mathrm{D}$ supplementation scenarios, respectively.
Average costs and quality-adjusted life-years (QALYs) were then computed and compared through an incremental cost-effectiveness ratio (ICER). The incremental costeffectiveness ratio (ICER) is calculated as follows:

ICER $=\frac{\text { Cost of new stratedy-cost of current practice }}{\text { Effect of new strategy-effect of current practice }}$

We programmed and ran 27 microsimulations: 3 age groups (65 years, 70 years, and 80 years), 3 baseline risks (women without low BMD or a PVF, women with a BMD T-score $<-2.5$, and women with a PVF), and 3 supplementation scenarios (1 U, $2 \mathrm{U}$, or $3 \mathrm{U}$ of $\mathrm{Ca} / \mathrm{Vit} \mathrm{D}$ diary supplementations per day). Each microsimulation was run 10 times with 200,000 patients to enable variability analyses. The average ICERs with its $95 \%$ confidence intervals were evaluated for each of the 27 microsimulations QALYs and costs were discounted at 1.5 and $3 \%$ respectively.

\section{Results}

The incremental cost-effectiveness ratios of the daily intake of 1,2 , or 3 portions of a vitamin D-fortified yogurt to women aged 65,70 , or 80 years, with no increased risk of osteoporosis (general population), low BMD, and PVF are summarized in Tables 1, 2, and 3 and in Fig. 2. Taking an upper limit of 45, $000 € /$ QALY as a threshold for cost-efficiency [26], one daily portion of yogurt is cost-effective in the general population above the age of 70 years and in all age groups in women with low BMD or PVF. The daily intake of two portions of yogurt is cost-effective above 80 years in the general population and above 70 years in the two groups of women at increased risk of fractures. However, an intake of three yogurts per day is only cost-effective above 80 years old in all three groups of women.

\section{Discussion}

This study is the first attempt to assess the cost-effectiveness of the daily intake of various amounts of a dairy product supplemented with vitamin D in women, at ages from 65 to 80 years and with or without prevalent osteoporosis. We selected a currently marketed yogurt which, as recommended by a recent published consensus guidance document for the management of osteoporosis [2] provides, in each portion, $40 \%$ of the RNI of calcium $(400 \mathrm{mg}$ ) and $200 \mathrm{IU}$ of vitamin D. Our results suggest that such a dietary supplementation in bonefriendly nutrients is cost-effective at ages varying from 65 to 80 years, depending on the prevalence of osteoporosis and on the number of portions required to reach the RNI. Low calcium intake in elderly subjects was repeatedly described, in the 
Table 1 Costs, QALYs, and ICER for a supplementation with one portion per day (125 Euros/year)

1 Unit/day (€125/year)

\begin{tabular}{|c|c|c|c|c|c|c|c|c|c|}
\hline & \multicolumn{2}{|c|}{$\mathrm{Ca} /$ Vit $\mathrm{D}$ supplementation } & \multicolumn{2}{|c|}{ No supplementation } & \multicolumn{2}{|c|}{ Incremental } & \multirow[t]{2}{*}{ ICER } & \multicolumn{2}{|l|}{$95 \% \mathrm{CI}$} \\
\hline & Cost & QALYs & Cost & QALYs & Cost & QALYs & & Low & High \\
\hline \multicolumn{10}{|c|}{ Women without low BMD or prevalent vertebral fracture } \\
\hline 65 years & $€ 6882$ & 12.793 & $€ 6461$ & 12.788 & $€ 421$ & 0.004 & $€ 94,304$ & $€ 18,369$ & $€ 170,239$ \\
\hline 70 years & $€ 7556$ & 10.183 & $€ 7222$ & 10.173 & $€ 333$ & 0.010 & $€ 34,513$ & $€ 16,406$ & $€ 52,620$ \\
\hline 80 years & $€ 7646$ & 5.622 & $€ 7701$ & 5.605 & $€ 55$ & 0.017 & $€ 3290$ & $€ 5036$ & $€ 1544$ \\
\hline \multicolumn{10}{|c|}{ Women with low BMD } \\
\hline 65 years & $€ 10,447$ & 12.655 & $€ 10,137$ & 12.643 & $€ 310$ & 0.012 & $€ 26,596$ & $€ 8465$ & $€ 44,726$ \\
\hline 70 years & $€ 10,823$ & 10.074 & $€ 10,607$ & 10.060 & $€ 217$ & 0.014 & $€ 15,183$ & $€ 10,448$ & $€ 19,918$ \\
\hline 80 years & $€ 9464$ & 5.571 & $€ 9685$ & 5.553 & $€ 221$ & 0.018 & $€ 12,237$ & $€ 15,405$ & $€ 9069$ \\
\hline \multicolumn{10}{|c|}{ Women with prevalent vertebral fracture } \\
\hline 65 years & $€ 9554$ & 12.528 & $€ 9195$ & 12.513 & $€ 359$ & 0.015 & $€ 24,345$ & $€ 14,736$ & $€ 33,954$ \\
\hline 70 years & $€ 10,452$ & 9.934 & $€ 10,174$ & 9.914 & $€ 279$ & 0.019 & $€ 14,328$ & $€ 11,841$ & $€ 16,814$ \\
\hline 80 years & $€ 10,360$ & 5.453 & $€ 10,614$ & 5.426 & $-€ 255$ & 0.027 & $-€ 9364$ & $-€ 11,793$ & $€ 6934$ \\
\hline
\end{tabular}

general population $[2,29]$ and in osteoporotic subjects $[2,8]$. A recent survey of calcium intake from calcium-dense dairy products in fracture patients reported a wide distribution of daily calcium intake in these patients with more than $60 \%$ of the subjects remaining below the RNI of $1 \mathrm{~g} /$ day [30]. This is in accordance with one of our previous studies, conducted in patients with established osteoporosis, issued from nine European countries and showing that, while close to $40 \%$ of the population took pharmacological calcium supplements, only a small subset of the patients had sufficient calcium intake [8]. In most studies assessing questionnaires evaluating calcium intakes, the standard deviation amounts up to $50 \%$ of the mean recorded value confirming large discrepancies between subjects and the need for a tailored supplementation based on the pre-existing calcium intake [31]. Similarly, vitamin D inadequacy is well documented in normal and osteoporotic subjects [5-7, 32] and the distribution of serum 25hydroxyvitamin D concentrations, the principal index of vitamin D status $[3,5,6]$, shows a wide scatter in the degree of deficiency and in the subsequent need for supplementation. Our study is the first to consider a personalized approach for calcium and vitamin D supplementation, tailoring the

Table 2 Costs, QALYs, and ICER for a supplementation with two portions per day (250 Euros/year)

2 Units/day (€250/year)

$\begin{array}{llllllll}\mathrm{Ca} / \text { Vit D supplementation } & & & \text { No supplementation } & & \text { Incremental } & \text { ICER }(€) & \frac{95 \% \text { CI }}{\text { Cost }(€)} \quad \text { QALYs }\end{array}$

Women without low BMD or prevalent vertebral fracture

$\begin{array}{llllllllll}65 \text { years } & 7228 & 12.796 & 6430 & 12.789 & 798 & 0.006 & 123,122 & 58,426 & 187,819 \\ 70 \text { years } & 7909 & 10.181 & 7201 & 10.170 & 709 & 0.011 & 62,975 & 38,000 & 87,951 \\ 80 \text { years } & 8005 & 5.620 & 7698 & 5.601 & 307 & 0.020 & 15,576 & 13,586 & 17,566\end{array}$

Women with low BMD

$\begin{array}{llllllllll}65 \text { years } & 10,763 & 12.653 & 10,105 & 12.641 & 658 & 0.012 & 56,498 & 43,655 & 69,340 \\ 70 \text { years } & 11,163 & 10.075 & 10,632 & 10.059 & 531 & 0.016 & 32,467 & 22,292 & 42,642 \\ 80 \text { years } & 9826 & 5.576 & 9673 & 5.554 & 153 & 0.022 & 6868 & 6076 & 7660\end{array}$

Women with prevalent vertebral fracture

\begin{tabular}{llllllllll}
65 years & 9942 & 12.533 & 9192 & 12.518 & 750 & 0.016 & 48,018 & 40,402 & 55,634 \\
70 years & 10,821 & 9.939 & 10,208 & 9.920 & 613 & 0.019 & 32,685 & 22,292 & 42,312 \\
80 years & 10,698 & 5.451 & 10,611 & 5.425 & 88 & 0.026 & 3390 & 2748 & 4032 \\
\hline
\end{tabular}


Table 3 Costs, QALYs, and ICER for a supplementation with three portions per day (375 Euros/year)

3 Units/day (€375/year)

\begin{tabular}{|c|c|c|c|c|c|c|c|c|c|}
\hline & \multicolumn{2}{|c|}{$\mathrm{Ca} /$ Vit $\mathrm{D}$ supplementation } & \multicolumn{2}{|c|}{ No supplementation } & \multicolumn{2}{|c|}{ Incremental } & \multirow[t]{2}{*}{$\operatorname{ICER}(€)$} & \multicolumn{2}{|l|}{$95 \% \mathrm{CI}$} \\
\hline & Cost $(€)$ & QALYs & Cost $(€)$ & QALYs & $\operatorname{Cost}(€)$ & QALYs & & Low $(€)$ & High $(€)$ \\
\hline \multicolumn{10}{|c|}{ Women without low BMD or prevalent vertebral fracture } \\
\hline 65 years & 7592 & 12.796 & 6418 & 12.788 & 1174 & 0.009 & 136,244 & 16,367 & 256,121 \\
\hline 70 years & 8272 & 10.187 & 7225 & 10.177 & 1047 & 0.010 & 104,523 & 62,106 & 146,941 \\
\hline 80 years & 8303 & 5.618 & 7728 & 5.602 & 575 & 0.015 & 37,114 & 31,264 & 42,964 \\
\hline \multicolumn{10}{|c|}{ Women with low BMD } \\
\hline 65 years & 11,105 & 12.656 & 10,093 & 12.641 & 1,012 & 0.014 & 71,058 & 53,694 & 88,422 \\
\hline 70 years & 11,505 & 10.074 & 10,608 & 10.057 & 897 & 0.018 & 51,002 & 45,738 & 56,266 \\
\hline 80 years & 10,132 & 5.570 & 9712 & 5.552 & 420 & 0.018 & 23,147 & 20,598 & 25,695 \\
\hline \multicolumn{10}{|c|}{ Women with prevalent vertebral fracture } \\
\hline 65 years & 10,290 & 12.531 & 9207 & 12.519 & 1083 & 0.012 & 89,303 & 79,780 & 98,826 \\
\hline 70 years & 11,117 & 9.934 & 10,168 & 9.918 & 948 & 0.016 & 58,001 & 47,837 & 68,165 \\
\hline 80 years & 11,039 & 5.451 & 10,633 & 5.423 & 407 & 0.028 & 14,602 & 13,502 & 15,702 \\
\hline
\end{tabular}

administration of these supplements based on the amounts of calcium and vitamin D that are already spontaneously received by the patients.

We recently reported that a pharmacological supplementation of vitamin $\mathrm{D}$ and calcium is cost-effective for women and men aged 60 years with osteoporosis [11]. This finding justifies the recommendation of the ESCEO working group to supplement all patients aged over 65 years with increased risk of fractures with calcium and vitamin D [2, 3]. This European consensus, however, recommends that dietary sources of nutrients are the preferred option for the supplementation of elderly subjects and that pharmacological supplementation should only be targeted to those individuals who do not get sufficient calcium from their diet [2]. Amazingly, this recommendation was never, before the present trial, justified in terms of cost-effectiveness. Our study is the first economic analysis that estimates the cost-effectiveness of calcium and vitamin D supplementation, given as a vitamin D-fortified yogurt, and taking into consideration the age $(65,70$, 80 years), the osteoporotic status (none, low BMD, PVF), and the amount of calcium (400 mg, $800 \mathrm{mg}, 1200 \mathrm{mg}$ ) and vitamin D (200 IU, $400 \mathrm{IU}, 600 \mathrm{IU})$ needed to reach the RNI. Whereas a previous study reported the impact of an increased dairy consumption on reducing the burden of osteoporosis in terms of health-outcomes and costs [9], our research is the first to provide a full economic analysis, using a validated and widely accepted Monte Carlo microsimulation model [13]. Another strength of our study relates to the sensitivity analyses assessing various supplementation regimens. However, if we rely on the average values of calcium intake in $25-\mathrm{OH}$ hydroxyvitamin D serum concentrations reported in the literature for normal and osteoporotic elderly subjects, and the
RNI for these nutrients [2, 3, 5-8, 22, 23, 29, 31-34], we can reasonably assume that an intake of two portions of a fortified yogurt per day in the general population and one portion in the low BMD and PVF groups, on top of the existing dietary and pharmacological intakes, would be appropriate to ensure an optimal coverage of the calcium and vitamin D requirements. In this case, this strategy is cost-effective above 80 years in the general population but as early as 65 years old in patients at increased risk of osteoporotic fracture. For those individuals, from the general population, with a higher than average spontaneous intake in calcium and vita$\min \mathrm{D}$, requesting only one portion of yogurt to reach the RNI, the strategy would be cost-effective from 70 years on while in those subjects with very low calcium/vitamin D intakes, who need three portions/day to compensate for their deficiency, cost-effectiveness will only be observed for all groups, above 80 years. Women with an increased risk of experiencing an osteoporotic fracture (low BMD or PVF) with an intermediate but less than average calcium and vitamin $\mathrm{D}$ intake, i.e., requesting two portions of yogurt per day to reach the RNI, would face a cost-effective strategy when aged 70 years and above.

Strength of this study includes the use of a rigorous systematic review on meta-analyses to assess the effects of calcium and vitamin D on fracture risk, which was conducted for our recent paper assessing the cost-effectiveness of pharmacological supplementation in calcium and vitamin D in elderly men and women with osteoporosis [11]. Our estimates are also probably conservative for several reasons. First, different studies showed that calcium and vitamin D supplementation have other health benefit effects. So, studies suggested that calcium and vitamin D may reduce the risk for breast cancer 

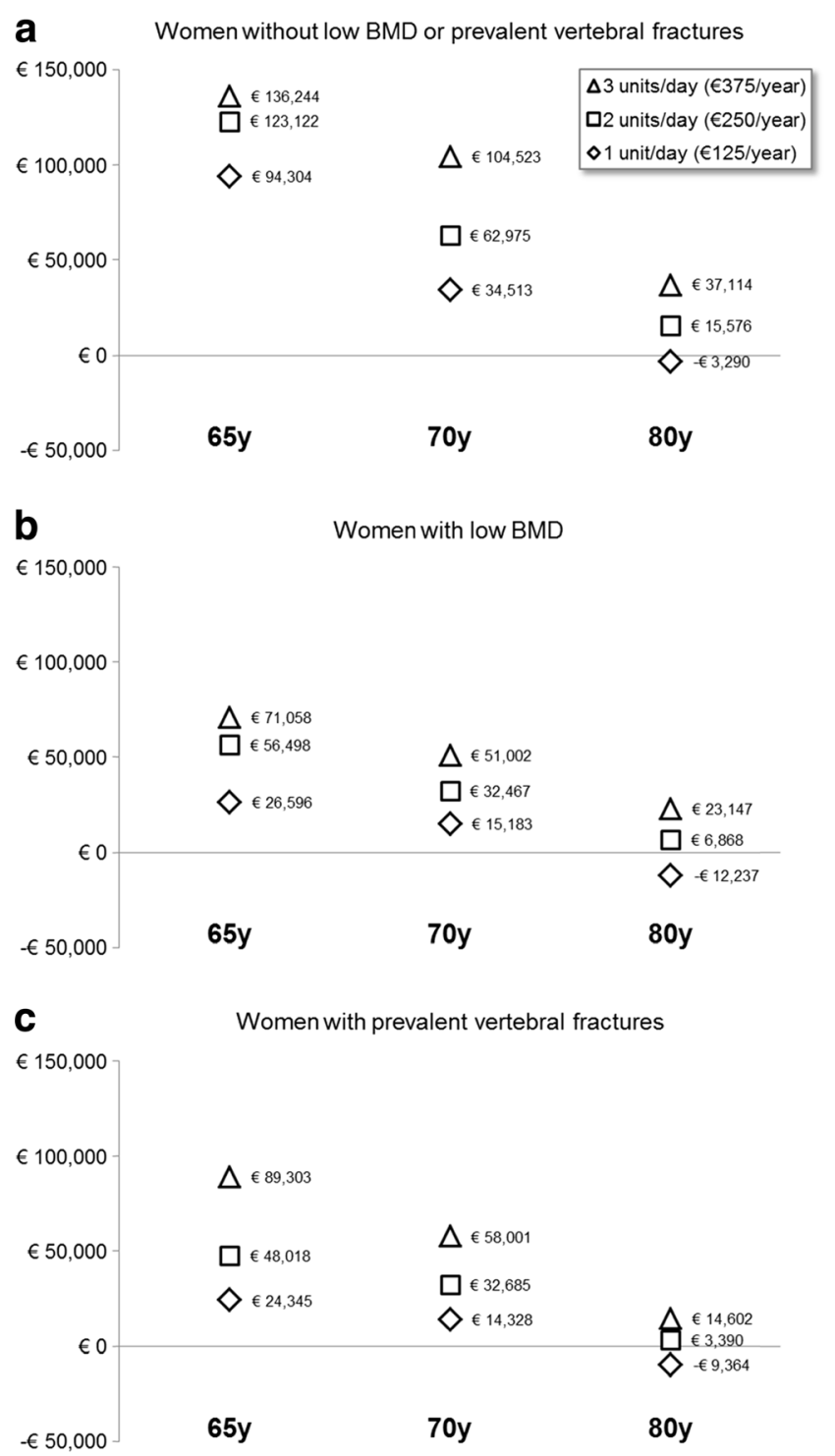

Fig. 2 a Incremental cost-effectiveness ratio of a supplementation with a dairy product fortified with vitamin D (400 mg calcium/200 IU vitamin D) as a function of age and cost of the dairy product (one daily portion: $125 €$, two daily portions: $250 €$, three daily portions: $375 €$ ) in women without low bone mineral density or prevalent vertebral fractures. b Incremental cost-effectiveness ratio of a supplementation with a dairy product fortified with vitamin D (400 mg calcium/200 IU vitamin D) as a function of age and cost of the dairy product (one daily portion: $125 €$, two daily portions: $250 €$, three daily portions: $375 €$ ) in women with low bone mineral density. c Incremental cost-effectiveness ratio of a supplementation with a dairy product fortified with vitamin D (400 mg calcium/200 IU vitamin D) as a function of age and cost of the dairy product (one daily portion: $125 €$, two daily portions: $250 €$, three daily portions: $375 €$ ) in women with prevalent vertebral fractures

mainly in premenopausal women [35] and colon cancer in older women [36]. A meta-analysis has also indicated that vitamin D may have a small beneficial effect on cardiovascular risk and mortality $[37,38]$. Second, we used a conservative assumption about the efficacy of calcium and vitamin D on hip fracture. In the article of Boonen et al., high doses of calcium and vitamin D were associated with a slightly greater reduction of hip fracture risk [22]. However, real-life studies, confirming that the administration of yogurt containing high doses of calcium and vitamin D provide the same extraskeletal benefits than pharmacological administration of calcium and vitamin $\mathrm{D}$ would be of greatest interest.

Third, at every stage of life, adequate dietary intakes of key bone nutrients including calcium, vitamin $\mathrm{D}$, and proteins contribute to muscle and bone health, thereby reducing the risk of falls, osteoporosis, and fractures in later life [3]. Dairy products are rich in proteins [33]. There is no clear-cut evidence that patients aged more than 65 years old have a deficit in protein intake similar to what is reported for calcium and vitamin D [29]. However, it is possible that our analysis, based only on the beneficial effects of calcium and vitamin D on bone, without modeling the potential benefits of proteins underestimates the positive outcomes of dairy products intake.

Our study could have some potential limitations that could inform further economic evaluations. Like any health economics study, there are a large number of assumptions. This analysis of the cost-effectiveness of yogurt supplementation in older women is critically dependent on the evidence for efficacy of the intervention. It should be reminded that controversy exists in the literature related to anti-efficacy of calcium supplements with some recent meta-analyses of the effects of calcium on hip fracture in community-dwelling older people challenging the reduction in fracture risk $[39,40]$. We did not incorporate adherence with dairy products which could potentially affect the cost-effectiveness of this strategy [41]. Limited information about adherence to dairy products is currently available including the impact of non-adherence on treatment efficacy. It should be reminded that in Tang [23] meta-analysis, compliance of $>80 \%$ is necessary to achieve anti-fracture efficacy. We also made the assumption that by supplementing patients with variable doses of dairy calcium and vitamin $\mathrm{D}$, based on their spontaneous intake of these nutrients (dietary or pharmacological), we would reach the target of at least $800 \mathrm{IU} /$ day of vitamin $\mathrm{D}$ and $1 \mathrm{~g} /$ day of calcium, hence getting a similar clinical benefit on fracture risk. We acknowledge that this assumption has not been tested in clinical trials.

In conclusion, our study is the first economic analysis supporting the cost-effectiveness of dairy products, fortified with vitamin $\mathrm{D}$, in the armamentarium against osteoporotic fractures. Dairy products have been repeatedly suggested as the most appropriate source of calcium and vitamin D supplementation in women at risk of osteoporotic fracture. Based on the average intake of these nutrients, reported in the literature, an additional daily intake of two portions in the general population and of one portion in women with low BMD or PVF, of a dairy product providing $400 \mathrm{mg}$ of calcium and $200 \mathrm{IU}$ of vitamin $\mathrm{D}$, would be appropriate to meet the RNI for these nutriments. This strategy would be cost-effective from the age 
of 80 years in the general population and as early as 65 years old in women with low BMD or PVF. We provide different sensitivity analyses based on the age of the women, the presence or absence of osteoporosis, and the amount of calcium and vitamin D needed to meet the RNI.

In future research, adherence of women either in the general population or at high risk of osteoporosis to dairy products might be tested in long-term prospective trials. It would also be of interest to design willingness to pay studies to better understand to which extend individuals are ready to add dairy products to their diet to prevent osteoporosis.

Acknowledgments This study was partially funded through an unrestricted educational grant from Danone, Paris, France. Danone did not influence the design of the analysis, was not involved in the preparation of the manuscript, and did not read the manuscript prior to its submission.

Conflicts of interest Olivier Ethgen has no relevant competing interests to declare.

Mickael Hiligsmann has received research grant and/or consulting fees from Amgen, Pfizer, Novartis, Servier and SMB

Nansa Burlet has no relevant competing interests to declare.

Jean-Yves Reginster has received research grant and/or consulting fees from Servier, Novartis, Negma, Lilly, Wyeth, Amgen, GlaxoSmithKline, Roche, Merckle, Nycomed-Takeda, NPS, IBSAGenevrier, Theramex, UCB, Asahi Kasei, Endocyte, Merck Sharp and Dohme, Rottapharm, Teijin, Teva, Analis, NovoNordisk, Ebewee Pharma, Zodiac, Danone, Will Pharma, Meda, Bristol Myers Squibb, Pfizer, Organon, Therabel, Boehringer, Chiltern, Galapagos

Open Access This article is distributed under the terms of the Creative Commons Attribution-NonCommercial 4.0 International License (http:// creativecommons.org/licenses/by-nc/4.0/), which permits any noncommercial use, distribution, and reproduction in any medium, provided you give appropriate credit to the original author(s) and the source, provide a link to the Creative Commons license, and indicate if changes were made.

\section{References}

1. (1993) Consensus development conference: diagnosis, prophylaxis, and treatment of osteoporosis. The American journal of medicine 94:646-650

2. Kanis JA, McCloskey EV, Johansson H, Cooper C, Rizzoli R, Reginster JY, Scientific Advisory Board of the European Society for C, Economic Aspects of O, Osteoarthritis, the Committee of Scientific Advisors of the International Osteoporosis F (2013) European guidance for the diagnosis and management of osteoporosis in postmenopausal women. Osteoporos Int: J Established Result Cooperation Between Eur Found Osteoporos Ntnl Osteoporos Found USA 24:23-57

3. Rizzoli R, Stevenson JC, Bauer JM et al (2014) The role of dietary protein and vitamin $\mathrm{D}$ in maintaining musculoskeletal health in postmenopausal women: a consensus statement from the European Society for Clinical and Economic Aspects of Osteoporosis and Osteoarthritis (ESCEO). Maturitas 79:122-132

4. Bruyere O, Cavalier E, Souberbielle JC, Bischoff-Ferrari HA, Beaudart C, Buckinx F, Reginster JY, Rizzoli R (2014) Effects of vitamin $\mathrm{D}$ in the elderly population: current status and perspectives. Arch Publ Health $=$ Arch Belges de Sante Publique 72:32
5. Rizzoli R, Boonen S, Brandi ML, Bruyere O, Cooper C, Kanis JA, Kaufman JM, Ringe JD, Weryha G, Reginster JY (2013) Vitamin D supplementation in elderly or postmenopausal women: a 2013 update of the 2008 recommendations from the European Society for Clinical and Economic Aspects of Osteoporosis and Osteoarthritis (ESCEO). Curr Med Res Opin 29:305-313

6. Bruyere O, Slomian J, Beaudart C, Buckinx F, Cavalier E, Gillain S, Petermans J, Reginster JY (2014) Prevalence of vitamin D inadequacy in European women aged over 80 years. Arch Gerontol Geriatr 59:78-82

7. Bruyere O, Malaise O, Neuprez A, Collette J, Reginster JY (2007) Prevalence of vitamin D inadequacy in European postmenopausal women. Curr Med Res Opin 23:1939-1944

8. Bruyere O, De Cock C, Mottet C, Neuprez A, Malaise O, Reginster JY (2009) Low dietary calcium in European postmenopausal osteoporotic women. Public Health Nutr 12:111-114

9. Lotters FJ, Lenoir-Wijnkoop I, Fardellone P, Rizzoli R, Rocher E, Poley MJ (2013) Dairy foods and osteoporosis: an example of assessing the health-economic impact of food products. Osteoporos Int: J Established Result Cooperation Between Eur Found Osteoporos Ntnl Osteoporos Found USA 24:139-150

10. Bolland MJ, Grey A, Reid IR (2013) Calcium supplements and cardiovascular risk: 5 years on. Ther Adv Drug Saf 4:199-210

11. Hiligsmann M, Ben Sedrine W, Bruyere O, Evers SM, Rabenda V, Reginster JY (2015) Cost-effectiveness of vitamin D and calcium supplementation in the treatment of elderly women and men with osteoporosis. Eur J Pub Health 25:20-25

12. Reginster JY (2007) Calcium and vitamin D for osteoporotic fracture risk. Lancet 370:632-634

13. Hiligsmann M, Ethgen O, Bruyere O, Richy F, Gathon HJ, Reginster JY (2009) Development and validation of a Markov microsimulation model for the economic evaluation of treatments in osteoporosis. Value Health: J Int Soc Pharmacoeconomics Outcomes Res 12:687-696

14. Hiligsmann M, Bruyere O, Roberfroid D, Dubois C, Parmentier Y, Carton J, Detilleux J, Gillet P, Reginster JY (2012) Trends in hip fracture incidence and in the prescription of antiosteoporosis medications during the same time period in Belgium (2000-2007). Arthritis Care Res 64:744-750

15. Kanis JA, Johnell O, Oden A, Sembo I, Redlund-Johnell I, Dawson A, De Laet C, Jonsson B (2000) Long-term risk of osteoporotic fracture in Malmo. Osteoporos Int: J Established Result Cooperation Between Eur Found Osteoporos Ntnl Osteoporos Found USA 11:669-674

16. Kanis JA, Oden A, Johnell O, Jonsson B, de Laet C, Dawson A (2001) The burden of osteoporotic fractures: a method for setting intervention thresholds. Osteoporos Int: J Established Result Cooperation Between Eur Found Osteoporos Ntnl Osteoporos Found USA 12:417-427

17. Kanis JA, Johnell O, De Laet C et al (2004) A meta-analysis of previous fracture and subsequent fracture risk. Bone 35:375-382

18. Klotzbuecher CM, Ross PD, Landsman PB, Abbott TA 3rd, Berger M (2000) Patients with prior fractures have an increased risk of future fractures: a summary of the literature and statistical synthesis. J Bone Mineral Res: Of J Am Soc Bone Mineral Res 15:721-739

19. Haentjens P, Magaziner J, Colon-Emeric CS, Vanderschueren D, Milisen K, Velkeniers B, Boonen S (2010) Meta-analysis: excess mortality after hip fracture among older women and men. Ann Intern Med 152:380-390

20. Hiligsmann M, Ethgen O, Richy F, Reginster JY (2008) Utility values associated with osteoporotic fracture: a systematic review of the literature. Calcif Tissue Int 82:288-292

21. Salaffi F, Cimmino MA, Malavolta N, Carotti M, Di Matteo L, Scendoni P, Grassi W, Italian Multicentre Osteoporotic Fracture Study G (2007) The burden of prevalent fractures on health- 
related quality of life in postmenopausal women with osteoporosis: the IMOF study. J Rheumatol 34:1551-1560

22. Boonen S, Lips P, Bouillon R, Bischoff-Ferrari HA, Vanderschueren D, Haentjens P (2007) Need for additional calcium to reduce the risk of hip fracture with vitamin d supplementation: evidence from a comparative metaanalysis of randomized controlled trials. J Clin Endocrinol Metab 92:1415-1423

23. Tang BM, Eslick GD, Nowson C, Smith C, Bensoussan A (2007) Use of calcium or calcium in combination with vitamin D supplementation to prevent fractures and bone loss in people aged 50 years and older: a meta-analysis. Lancet 370:657-666

24. Bischoff-Ferrari HA, Willett WC, Wong JB, Stuck AE, Staehelin HB, Orav EJ, Thoma A, Kiel DP, Henschkowski J (2009) Prevention of nonvertebral fractures with oral vitamin $\mathrm{D}$ and dose dependency: a meta-analysis of randomized controlled trials. Arch Intern Med 169:551-561

25. Zethraeus N, Borgstrom F, Strom O, Kanis JA, Jonsson B (2007) Cost-effectiveness of the treatment and prevention of osteoporosisa review of the literature and a reference model. Osteoporos Int: J Established Result Cooperation Between Eur Found Osteoporos Ntnl Osteoporos Found USA 18:9-23

26. Cleemput I, van Wilder P, Huybrechts M, Vrijens F (2009) Belgian methodological guidelines for pharmacoeconomic evaluations: toward standardization of drug reimbursement requests. Value Health: J Int Soc Pharmacoeconomics Outcomes Res 12:441-449

27. Autier P, Haentjens P, Bentin J, Baillon JM, Grivegnee AR, Closon MC, Boonen S (2000) Costs induced by hip fractures: a prospective controlled study in Belgium. Belgian Hip Fracture Study Group. Osteoporos Int: J Established Result Cooperation Between Eur Found Osteoporos Ntnl Osteoporos Found USA 11:373-380

28. Melton LJ 3rd, Gabriel SE, Crowson CS, Tosteson AN, Johnell O, Kanis JA (2003) Cost-equivalence of different osteoporotic fractures. Osteoporos Int: J Established Result Cooperation Between Eur Found Osteoporos Ntnl Osteoporos Found USA 14:383-388

29. Fernandez-Barres S, Martin N, Canela T, Garcia-Barco M, Basora J, Arija V, A-NUTg P (2015) Dietary intake in the dependent elderly: evaluation of the risk of nutritional deficit. J Human Nutr Die: Off J Br Diet Assoc

30. van den Berg P, van Haard PM, van den Bergh JP, Niesten DD, van der Elst M, Schweitzer DH (2014) First quantification of calcium intake from calcium-dense dairy products in Dutch fracture patients (the Delft cohort study). Nutrients 6:2404-2418

31. Macdonald HM, Black AJ (2015) Validation of a short questionnaire for estimating dietary calcium intakes. Osteoporos Int: J Established Result Cooperation Between Eur Found Osteoporos Ntnl Osteoporos Found USA 26:837

32. Neuprez A, Bruyere O, Collette J, Reginster JY (2007) Vitamin D inadequacy in Belgian postmenopausal osteoporotic women. BMC Public Health 7:64

33. Rizzoli R (2014) Dairy products, yogurts, and bone health. Am J Clin Nutr 99:1256S-1262S

34. Wlodarek D, Glabska D, Kolota A, Adamczyk P, Czekajlo A, Grzeszczak W, Drozdzowska B, Pluskiewicz W (2014) Calcium intake and osteoporosis: the influence of calcium intake from dairy products on hip bone mineral density and fracture incidence- a population-based study in women over 55 years of age. Public Health Nutr 17:383-389

35. Chen P, Hu P, Xie D, Qin Y, Wang F, Wang H (2010) Meta-analysis of vitamin $\mathrm{D}$, calcium and the prevention of breast cancer. Breast Cancer Res Treat 121:469-477

36. Murphy N, Norat T, Ferrari P et al (2013) Consumption of dairy products and colorectal cancer in the European Prospective Investigation into Cancer and Nutrition (EPIC). PLoS One 8, e72715

37. Bjelakovic G, Gluud LL, Nikolova D, Whitfield K, Wetterslev J, Simonetti RG, Bjelakovic M, Gluud C (2014) Vitamin D supplementation for prevention of mortality in adults. Cochrane Database Syst Rev 1, CD007470

38. Wang L, Manson JE, Song Y, Sesso HD (2010) Systematic review: vitamin $\mathrm{D}$ and calcium supplementation in prevention of cardiovascular events. Ann Intern Med 152:315-323

39. Reid IR, Bolland MJ (2014) Calcium risk-benefit updated-new WHI analyses. Maturitas 77:1-3

40. Bischoff-Ferrari HA, Dawson-Hughes B, Baron JA et al (2007) Calcium intake and hip fracture risk in men and women: a metaanalysis of prospective cohort studies and randomized controlled trials. Am J Clin Nutr 86:1780-1790

41. Hiligsmann M, Boonen A, Rabenda V, Reginster JY (2012) The importance of integrating medication adherence into pharmacoeconomic analyses: the example of osteoporosis. Expert Rev Pharmacoeconomics Outcomes Res 12:159-166 